\title{
Performing High Resolution Seismic Reflection for Mapping Bauxite Layers
}

\author{
A. Qadrouh, A. Alanezi, I. Hafiz, K. Munir, M. Alyousif \\ Seismic Analyses Center, King Abdulaziz City for Science and Technology (KACST), Riyadh, Saudi Arabia \\ Email: aqadrouh@kacst.edu.sa
}

Received 2013

\begin{abstract}
The seismic method is able to produce highly accurate images of the Earth's subsurface. Having such detail is not only an important factor in mining, but also in civil engineering. Bauxite exploration attracts both government and industrialists to invest in it because of the high percentage of aluminum present. The economic importance of extracting aluminum from bauxite encouraged us to take this challenge; to image bauxite layers by using a high-resolution seismic reflection method at Al Qassim, Saudi Arabia. Since the subsurface structure of the area is complex, this high-resolution reflection method was carried out along a 2D line with geophone and source interval, with settings at $5 \mathrm{~m}$. The result for the seismic section shows that the depth and thickness of the bauxite layer varied from 20 to $34 \mathrm{~m}$, and 3 to $7 \mathrm{~m}$ respectively. In addition, the bauxite layer was sandwiched between clay layers. In order to achieve an even more precise depth than presented by seismic section alone, we tied the drilled wells to the seismic data and we accomplished a well match with an approximation error of $1-2 \mathrm{~m}$, which may have been caused by the upper clay layer or by very shallow loose subsurface material. The seismic method thus applied shows the ability to detect significant details within the near surface of the earth, and considers more cost-effective than only drilled wells.
\end{abstract}

Keywords: High-resolution Seismic Reflection Method; Depth Conversion; Bauxite

\section{Introduction}

The high-resolution seismic reflection method has performed effectively to delineate the subsurface structures of the earth. Many geophysicists such as [6], [12], [10] and [7] have detected coal using this method. Other investigators have utilized the high-resolution seismic reflection method for a variety of applications. For example, [8] applied it to determine unconsolidated sedimentary structures in the Netherlands. [5] applied the method to detect unconsolidated aquifers in Australia. [4] used it to assist in mine planning and future horizontal drilling for coal-seam methane extraction. [13] applied it to image a thin, diamondiferous kimberlite dyke. Clement et al. (2010) used it to delineate growth folding and shallow faults beneath the southern Puget Lowland, Washington state.

Approximately $85 \%$ of bauxite are considered to be aluminum, where aluminum has specific physical and chemical characteristics such as light weight, low density, great strength and resistant to oxidation [9]. Such high percentages have attracted government and industrialists to invest in bauxite extraction for the revenue provided. Many researchers have applied various geophysical methods to detect bauxite layers, such as [11] who ap- plied a seismoelectric method, [14] who performed the electrical tomography technique, as well as GPR and [2] who applied induced polarization sounding and resistivity methods.

The ultimate objective of our research was to apply the high-resolution seismic reflection method to delineate the bauxite layer at the $\mathrm{Al}$ Qassim site in Saudi Arabia. Once accomplished, the seismic result was tested with both drilled wells and lithological data to confirm the depth and thickness of the bauxite layer. The results show that this layer generally varied in depth and thickness, from 20 to $35 \mathrm{~m}$ and 3 to $7 \mathrm{~m}$ respectively, sandwiched between clay layers. The wells were tied to the seismic reflection section and we achieved a good match, with an error of approximately $1-2 \mathrm{~m}$, which may have been caused by the upper clay layer or very shallow loose subsurface material.

\section{Field Procedures and Data Processing}

When acquiring high-resolution seismic reflection data, it is essential to avoid aliasing problems, which can be avoided by collecting signals with sufficient spatial and temporal sampling. The high-resolution reflection method was carried out along a 2D seismic line. Our geometry 
pattern adopted the approach of [1]. The geophone group interval and the shotpoint interval were $5 \mathrm{~m}$, with each record composed of 48 channels as shown in Figure 1. The geophone spread consists of 48 receivers with interval of $5 \mathrm{~m}$. Three cables were used, shown as A, B and C, with geode connections. Shootings were performed in between the geophones starting from cable B, and data was recorded for the first 16 shots, indicated by red stars. Then cable A was moved in front of cable B and C, and the process was repeated for the next 16 shots and thus repeated until 64 shots were recorded. The selected field parameters in this study are shown in Table1.

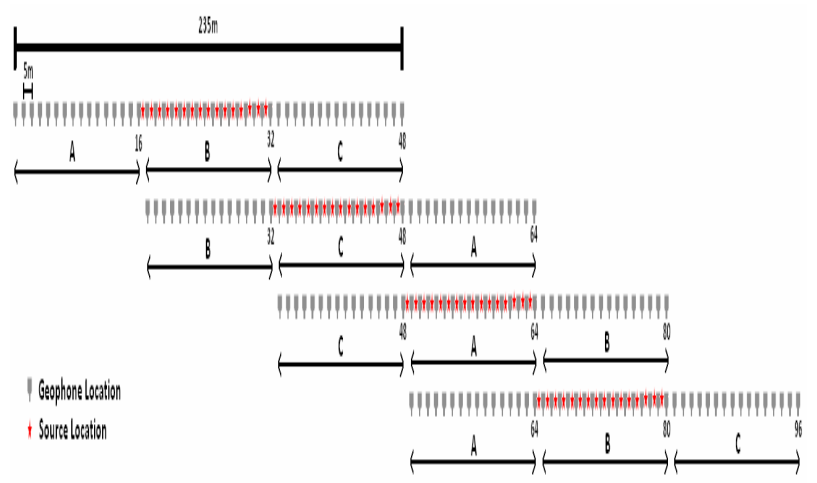

Figure 1. Geophone array with shot locations pattern.

Table1. Field parameters.

\begin{tabular}{lc}
\hline & SPREAD \\
\hline Type & Mid spread shooting \\
Number of trace & 48 traces \\
Receiver interval & $5 \mathrm{~m}$ \\
Source interval & $5 \mathrm{~m}$ \\
Near Offset & $2.5 \mathrm{~m}$ \\
Max. Offset & $157.5 \mathrm{~m}$ \\
Nominal CDP Fold & 32 Fold \\
& SOURCE \\
Type & Weight Drop \\
No. of Weight Drop (80kg) & One \\
& RECEIVER \\
Type & Geophone Flat base \\
Model & GS $-20 \mathrm{DH}$ \\
Response & 365 ohm , 40 Hz , 0.70 Damping \\
& INSTRUMENT \\
Type & Geometrics , Strata Visor NZ \\
Sampling interval & 0.125 \\
Gain constant & $36 \mathrm{~dB}$ \\
Record length & $500 \mathrm{~ms}$ \\
Filter & out \\
\hline
\end{tabular}

The primary objectives of seismic data processing are to produce high resolution images of the subsurface, achieved by enhancing signal to noise ratio and migrating the reflected waves to their correct position. The conventional processing sequence of seismic reflection data include, but are not limited to: filtering, statics application, de-reverberation, CMP sorting, velocity analysis, NMO correction and stacking. Figure 2 and Figure 3 show the stacked seismic section in time scale and the appropriate processing sequencing, in order to obtain better signal enhanced results respectively.

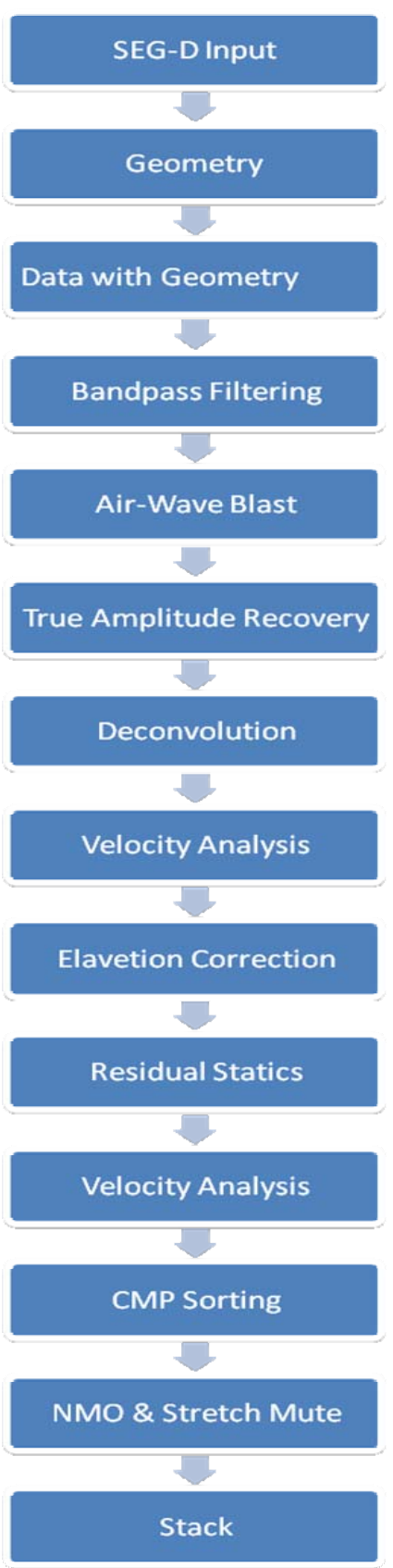

Figure 2. The processing steps in this research. 


\section{Interpretation of the Results}

The stacked section was interpreted in order to identify the bauxite layer across the survey area. The interpretation was begun by transforming the seismic section from time (millisecond) to depth (meter), where the accuracy of such depth conversion depends on how accurate the processing of seismic data is; that is to say, accurate depth conversion depends on the accuracy of velocities and times recorded. We applied the interval velocity approach to convert the data from time to depth scale. The results of the seismic section show that the depth and thickness of the bauxite layer varied as previously described. In order to achieve a more precise depth interpretation than that provided only by seismic section, we tied two drilled wells to the seismic data. Table 2 shows the detail information about the two drilled wells integrated with seismic section to mark the bauxite related horizon. Figure 4 shows the well locations in blue color, with the red color in blue traces marking the depth range of the bauxite layer, from 27 to $34 \mathrm{~m}$ for Well A, and 25 to $28.5 \mathrm{~m}$ for Well $\mathrm{B}$. The green dotted line marks the horizon related to the bauxite layer after correlating the bauxite depths from the wells. Figure 5 reveals the lithological data, combined with stacked section and the two drilled wells, in order to confirm the position of the bauxite layer. As a result, we accomplished a well match, with an approximation error of just 1 to $2 \mathrm{~m}$, which may have been caused by near surface complexities.

\section{Conclusions}

Clearly, this research has emphasized the robustness of using the high-resolution seismic reflection method to

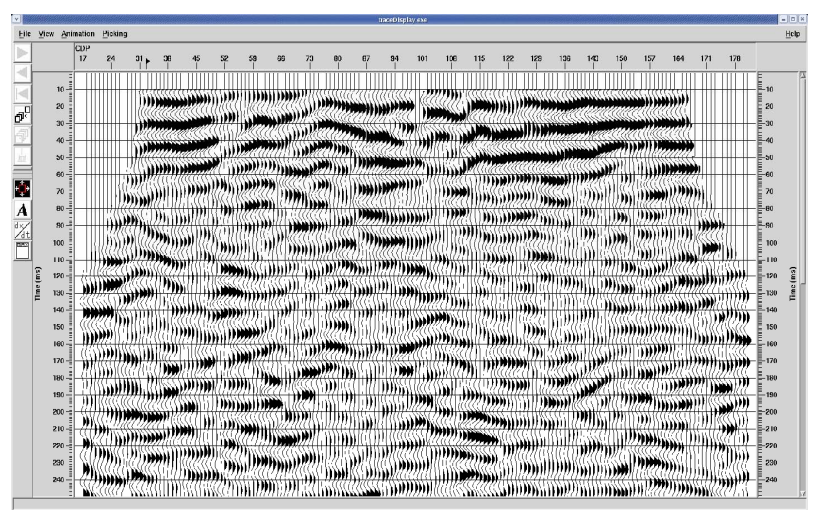

Figure 3. The stacked seismic section in time scale.

Table 2. The Well-A and Well-B derived information.

\begin{tabular}{lcc}
\hline \multicolumn{1}{c}{ Wells information } & WELL - A & WELL - B \\
\hline Distance from 1 $\mathbf{1}^{\text {st }}$ Geophone (m) & 80 & 195 \\
Bauxite depth range (m) & $27-34$ & $25-28.5$ \\
Thickness (m) & 7 & 3.5 \\
\hline
\end{tabular}

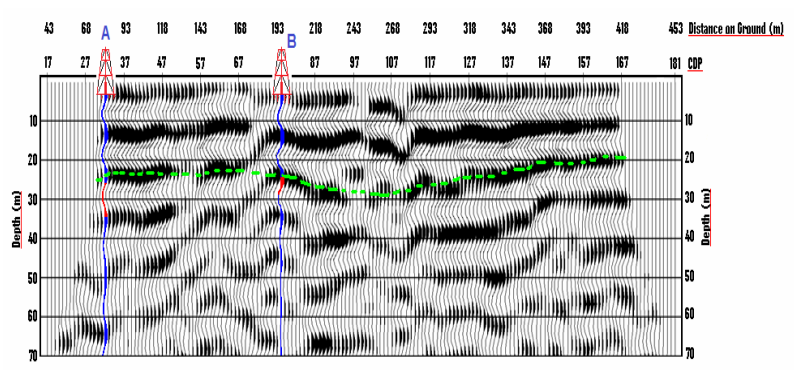

Figure 4. The wells locations and bauxite layer present by blue and green color respectively.

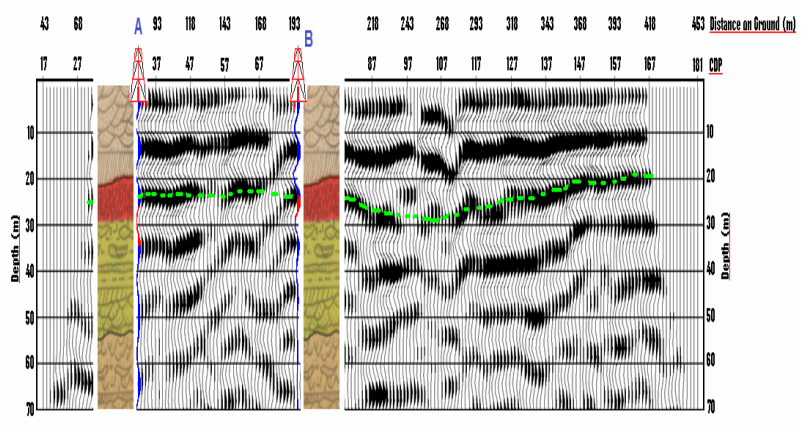

Figure 5. Lithological data combine with stacked section and two drilled wells to confirm the position of bauxite layer.

map a bauxite layer, and it is considered more cost-effective than drilling. In this study, the bauxite layer had been imaged by utilizing this method, combined with two drilled wells and lithological data tied to the seismic profile. The combined available data successfully confirmed the location of the bauxite layer with minimal error. With a high rate of accuracy and improved cost effectiveness, the high-resolution seismic reflection method as described provides clear benefits for all concerned.

\section{Acknowledgements}

The authors wish to thank KACST for valuable knowledge and data of this research. The authors also would like to thank Taiseer Al Yaqoob who generously sharing his knowledge and experience.

\section{REFERENCES}

[1] B. Benjumea, J. A. Hunter, R. L. Good, R. A. Burns and M. Ross, "Application of High-Resolution Seismic-Reflection Techniques in Champlain Sea sediments near Lachute-Saint-Benoit,” Quebec, Natural Resources Canada, 2001, doi:10.4095/212156

[2] B. K. Bi, "The Application of the Electric Method to Bauxite Exploration: Geophysical and Geochemical Exploration,” Vol. 33, 2009, pp. 400-402.

[3] C. R. Clement, T. L. Pratt, M. L. Holmes and B. L. Sherrod, "High-Resolution Seismic Reflection Imaging of 
Growth Folding and Shallow Faults beneath the Southern Puget Lowland, Washington State," Bulletin of the Seismological Society of America, Vol. 100, 2010, pp. 1710-1723. doi:10.1785/0120080306

[4] J. Cocker, M. Urosevic and B. Evans, “A High Resolution Seismic Survey to Assist in Mine Planning," Proceeding of Fourth Decennial International Conference on Mineral Exploration, edited by A. G. Gubins, 1997, pp. 473 - 476.

[5] P. E. Geissler, "Seismic Reflection Profiling for GroundWater Studies in Victoria,” Australia Geophysics, Vol. 54, 1989, pp. 31 - 37.

[6] S. Greenhalgh, M. Suprajitno and D. King, "Shallow Seismic Reflection Investigations of Coal in the Sydney Basin,” Geophysics, Vol. 51, 1986, pp. 1426-1437.

[7] H. Henson, J. Sexton and J. Jobling, "High - Resolution Seismic Reflection Study of Shallow Coal Seams Near Harco, Illinois,” SEG Technical Program Expanded Abstracts, 1989, pp. 372-374.

[8] P. Jongerius and K. Helbig, "Onshore High-resolution Seismic Profiling Applied to Sedimentology, Geophysics,” Vol. 53, 1998, pp. 1276-1283.

doi:10.1190/1.1442405
[9] C. Klein and C. S. Hurlbut, "Manual of Mineralogy," John Wiley and Sons Publishers, Canada, 1993.

[10] R. Knapp and A. Ertan Muftuoglu, "Detection of Coals $30 \mathrm{~cm}$ Thick at Depths of 50 and $60 \mathrm{~m}$ by Seismic Reflection Profiling,” SEG Technical Program Expanded Abstracts, 1987, pp. 227-228.

[11] N. Neishtadt, L. Eppelbaum and A. Levitski, “Application of Seismo-Electric Phenomena in Exploration Geophysics: Review of Russian and Israeli Experience,” Geophysics, Vol. 71, 2006, pp. 41-53. doi:10.1190/1.2187714

[12] D. Palmer, "High Resolution Seismic Reflection Surveys for Coal,” Geoexploration, Vol. 24, 1987, pp. 397-408. doi:10.1016/0016-7142(87)90009-3

[13] T. C. H. Philip, M. C. Ron and R. Kumar, "High-Resolution Seismic Reflection Imaging of a Thin, Diamondiferous Kimberlite Dyke,” Geophysics, Vol. 69, 2004, pp. 1143-1154. doi:10.1190/1.1801932

[14] P. Tsourlos, G. Tsokas and A. Yiamas, "Derecting Bauxitic Lenses in Galleries Using Geophysicsal Techniques: Proceeding of the Conference of the Committee of Economic Geology, Mineralogy, Geochemistry of the Greek geological Society,” Thessaloniki, 2005, pp. 367-376. 